\title{
Learning to shield - Policy learning in socio-technical transitions
}

Wouter Boon $^{1^{*}}$ and Sjoerd Bakker ${ }^{2}$

Please cite as: Boon, W.P.C., \& Bakker, S. (2016) Learning to shield-Policy learning in socio-technical transitions. Environmental Innovation and Societal Transitions 18: 181200.

${ }^{1}$ Innovation Studies, Copernicus Institute of Sustainable Development, Utrecht University, Heidelberglaan 2, 3584 CS Utrecht, the Netherlands

${ }^{2}$ OTB Research Institute, Faculty of Architecture and the Built Environment, Delft University of Technology, Jaffalaan 9, 2628 BX Delft, the Netherlands

${ }^{*}$ Corresponding author:

Wouter P.C. Boon

Innovation Studies, Copernicus Institute of Sustainable Development, Utrecht University, Heidelberglaan 2, 3584 CS Utrecht, the Netherlands

w.p.c.boon@uu.nl

Phone number: +31(0)302532708 


\title{
Learning to shield - Policy learning in socio-technical transitions
}

\begin{abstract}
The dynamics of protection in the context of socio-technical niches have remained underresearched. In this paper we conceptualise the process of policy learning in the context of transitions. We show that a variety of actors inside and outside a technological niche have to learn about the implications and effects of regulations aimed at protection of niches. We analyse this process of policy learning in two cases: high-need drugs and electric vehicles. We conclude that both regulators and the regulated need to learn about the width and depth of protection measures, their duration, the specific set of tools used, and their legitimisation. A crucial issue of implementing protective regulation is the question on what level of aggregation protection measures need to be applied. Learning is often part of the negotiation process between the protector and the protected, but in many cases learning only takes place after policies have been implemented.
\end{abstract}

\section{Keywords}

Protective space, niche, regulation, learning, electric vehicles, pharmaceutical sector.

\section{Introduction}

Emerging technologies are characterised as being malleable and immature. Several dimensions of these technologies are still to be fleshed out and developed in order to meet the level needed to fight off competition from incumbent technologies (Rip 1995). Literature on socio-technical transitions describes these dynamics by examining niches in which these early-stage technologies are protected, creating room for experimentation and maturation (Kemp et al. 1998; Schot and Geels 2008).

These spaces are called protective spaces or socio-technical niches. In the last decade and a half, such technological niches have been vigorously investigated in a wide range of case studies. Most attention has been paid to the activities taking place inside these niches, i.e. the 
way in which learning, articulating expectations and network building strengthen technology development in protective spaces (Kemp et al. 1998; Schot and Geels 2008). These studies explicitly included an analysis of the policies that support individual pilot projects (e.g. Kemp, Schot and Hoogma 1998; Raven 2005; Caniëls \& Romijn 2008), or policies that force industries to offer more sustainable products and which create an early market for otherwise too costly and typically underperforming solutions. They also focussed on assessments of the effectiveness of these protection measures (Nill and Kemp 2009; Kemp and Pontoglio 2011).

These studies have, however, not sought an answer to the question what niche protection really entails and how it is developed. In this vein, Smith and Raven (2012) recently emphasised how the nature and dynamics surrounding protection have remained underconceptualised, despite it being a key element of transitions thinking. In other words, we still do not really know "what protection is, where protection comes from, how it is contested, who is involved in shaping protection, nor how protection is transformed and declines as transitions come about” (Smith and Raven 2012). Their attempt to conceptualise niche protection and to answer the questions above hinges on a better understanding of the politics involved in transitions and hence in niche protection ${ }^{1}$.

This emphasis on agency and the politics of transitions has been advanced in recent transition literature (Smith et al. 2005; Kern 2011; Smith and Stirling 2010; Bakker 2014; Geels 2014; Markard et al. 2015). In the context of niche protection, Ulmanen et al. (2009) adduced the notion of agency and politics by showing that protection is produced by a wide range of actors rather than public authorities alone. They also find that the evolution of protection is the result of actors who strategically lobby, negotiate and mobilise discourses.

Building on this, creating protection as a long-term and complex process involving multiple actors and levels points to the need for continuous evaluation and adaption. Actors do not know beforehand what their interests exactly are in relation to the transition pathway, nor do they know how various policies will affect them or the proposed transition (Kern 2011). This is something that all actors need to learn along the way, indicating a need for reflexive governance (Voß et al. 2009).

With this paper we aim to shed led light on the learning processes that actors go through in creating and sustaining technological niches by means of (public) policy. Current literature on

\footnotetext{
${ }^{1}$ In this special issue Raven and colleagues present a meta-study of six empirical cases of niche construction and empowerment (Raven et al. 2015).
} 
protective spaces has paid relatively little explicit attention to policy learning, which is slightly odd given its importance in the shaping of protective space. This leads us to the research question central to this paper: how does policy learning shape protective spaces? We address this question in two ways.

First, we mobilise literature on policy learning. Putting this mastering of protective policies in a broader perspective, we aim to conceptualise 'policy learning' and thereby add to literature on the relationship between innovation and policy/regulation (Grabowski et al. 1978; Rothwell 1992; Wiener 2004; Blind 2012). Building on policy studies, we distinguish five dimensions of policies for protection (Dunn 1994; Schneider and Ingram 1997, p.102): the width, depth, duration, tools, and legitimisation of policies.

Second, we empirically investigate the relationships between policy and protective spaces using these dimensions in two cases: the pharmaceutical and the automotive sector. Both sectors can be characterised as having a high degree of regulator-regulated interactions and are concerned with unmet societal needs that are contested by different stakeholders. The remainder of the paper is structured as follows. In Section 2 the theoretical background is introduced. Section 3 elaborates the research methods and Section 4 analyses policy learning in the context of our two cases. Finally, Section 5 concludes the paper and reflects upon the findings.

\section{Theoretical perspective on understanding protective regulation}

\subsection{Niche protection}

To conceptualise patterns in socio-technical transitions, a multi-level perspective is proposed that discerns three levels, i.e. a socio-technical landscape, regimes (established practices and rules) and niches. Radical innovations developed in these niches need protection from the rigours of an existing socio-technical regime, resulting in anything extraordinary effectively being shut out (Hoogma et al. 2002; Raven 2006). These rigours stem from stabilised market selection criteria that have co-evolved with old solutions and that new technologies often cannot meet. Other rigours include routines and capabilities of an existing industry, and formal regulations and standards to which new technologies do not comply (Smith and Raven 2012). Some form of protection is thus necessary to overcome these barriers and to support the radical innovation to the point at which it can take on the regime 'on its own'. In practice 
this means that, for instance, the innovation needs to improve, but also that a network of supporting actors needs to grow and that niche outsiders need to be convinced of its future (Schot et al. 1994). Niche protection may take the form of one or more pilot projects in which innovations are tested and developed further. Protection may also be realised through a set of policy measures aimed at shielding the emerging technology. Such measures may include financial schemes for technology development and commercialisation, market subsidies, regulatory exemptions, etc. The success of early-stage development in these niches is conceptualised in the literature as a bottom-up process in which niche practices break out to the regime. Along the way, the rules of this regime change to suit the novel technology or the regime gets overthrown in its entirety (Geels and Schot 2007).

As was introduced in the previous section, active and deliberate protection forms an essential, yet under-conceptualised aspect of niches. First and foremost, it remains unclear what protection entails. Early studies perceived technological niches as experiments (Geels and Raven 2006). Strategic Niche Management (SNM) proposed to organise consecutive experiments to create an on-going process of learning, articulating, networking and expectations building. In this perspective, protection is organised at the local scale and mainly by local actors. When studying these local experiments SNM scholars have mostly focused on niche-internal dynamics (Kemp et al. 1998; Schot and Geels 2008). More recently, attention has shifted to broader conceptions of technological niches (Geels and Raven 2006) that views niche protection as more dispersed across locations and groups of actors. In terms of locations, next to local niches consisting of experiments, one can also recognise a global niche for, say, photovoltaic panels, which is just as much shaped by international agreements on climate goals and renewable energy production targets as it is by local consumer incentives or experimental neighbourhoods with zero-energy buildings. In terms of stakeholder groups, protection is not only created by public agencies but also involves a wider set of actors (Ulmanen et al. 2009; Garud and Rappa 1994). Protection can be regarded as the result of an interplay between niche insiders and outsiders (cf. Garud and Ahlstrom 1997), as well as actors directly affected by protective measures, e.g. patients or car owners.

So, recent studies focus on a broader conceptualisation of niche protection. Less attention has been paid to the interplay between a wide range of actors and localities leading to the creation and maintenance of protective policy measures, and to what extent such interactions led to changes over time in stakeholders' demands, policy measures and/or niche protection. We 
aim to contribute to this void by rethinking the notion of protection and the way in which policy learning is influencing protection.

\subsection{Policy learning}

A premise underlying our approach to niche protection is that both insiders and outsiders are involved in the implementation of protection measures. With protection being (partially) dependent on policy measures, we relate to debates about interrelations between regulation and innovation. Traditionally, scholars have emphasised the hampering impact of regulation on innovation activities (Irwin et al. 1997). Reasons for this include additional costs of compliance, uncertainty about the regulators and regulations, and restrictions imposed by the regulations (Chappin 2008). On the other hand, Porter and Van der Linde (1995) propose that (environmental) regulations can also advance innovation. Reasons for this include the creation of a level playing field, decreased uncertainty over investment choices, and the articulation of companies' visions. A meta-study on Porter's hypothesis concluded that stricter regulation indeed leads to more innovation, but that the overall influence on business performance is rather mixed (Ambec et al. 2013). The picture of the impact of regulation on innovation becomes even more diffuse when taking differences in sector, time horizon, company characteristics and type of regulation into account (Blind 2012).

Engaging in innovation-regulation interactions can be regarded as a part of a process of policy learning (Grin and Loeber 2006). Following Hall’s (1993) definition, policymaking is regarded as social learning that is "a deliberate attempt to adjust the goals or techniques of policy in response to past experiences and new information. Learning is indicated when policy change is the result of such a process”. Majone and Wildavsky (1979) take this policy evolution perspective one step further by conceptualising policymaking as an evolutionary process of trial-and-error search for feasible policy solutions. Trial-and-error searching is not necessarily based on systematic evaluations or a complete understanding of cause-and-effect relations underlying policy measures, i.e. testing the 'policy theory'. Rather, trial-and-error searching can simply yield insights into the desirability of policy outcomes (Bennett and Howlett 1992; May 1992).

Several policy scientists have distinguished different types of policy learning. They conceptualised trial-and-error as a mode of first-order learning (Argyris \& Schon 1978) or 
instrumental learning, i.e. technical learning about the policy instruments and their effects (Glasbergen 1996). In addition, Sabatier (1993) underlines the importance of 'policy core beliefs' forming the slow-changing and underlying basis of policymaking. Therefore, besides first-order learning, developing these underlying assumptions is proposed as reflexive or second-order learning (Argyris and Schon 1978; Ven et al. 1999). Second-order learning encompasses both learning about concepts and problem definitions as well as about values (cf. conceptual and social learning: Glasbergen 1996). Grin and Van de Graaf (1996) conceived these two learning processes as integral to policymaking, which involves developing "policy programs (comprising objectives, ends, and means) that affect social reality in a manner consistent with the policy coalition's ontological ideas about social reality. A policy program is interpreted by a coalition against the background of its appreciative systems and overarching theories”. Such policy formation processes deal with 'feasibility testing' of policy measures that systematically takes underlying values of different stakeholders involved into account. This might link the protective policy measures with the narratives that are used in niche empowerment activities (Smith and Raven 2012).

At the same time, by embracing coalitions Grin and Van der Graaf emphasise that policymaking and policy learning does not happen in isolation. This follows Sabatier (1993) who perceives stakeholders in the policy process as part of 'advocacy coalitions' which can learn about policy choices based on technical information resources as well as beliefs. Such a perspective explicitly includes a wide range of stakeholders who might hold different but congruent meanings. In the interplay of coalitions, actors articulate political accounts that articulate sets of ideas and beliefs that favour certain interests, i.e. narratives, in an effort to validate or legitimise the social practice introduced by the regulations (Cajaiba-Santana 2014; see also Lockwood 2015 in this issue). Therefore, narratives play a key role in negotiating and learning about protective measures (Garud and Rappa 1994).

The emphasis of our paper is, thus, on policy learning in relation to the protection of technological niches. Learning takes place among different actors and we argue that they learn about various aspects of protection and that the lessons learnt are fed back into ongoing negotiations. Learning is perceived here as an interactive process with no clear or optimal end goal in mind, i.e. there is no learning towards full consensus nor perfect shielding measures. We can, however, expect that some dimensions of niche protection are vital to the negotiations. Actors need to learn about the effect of various measures on the development of the niche and the impact they have on the individual actors. In defining these dimensions we 
take elements of policy design structures as proposed by Dunn (1994) and Schneider \& Ingram (1997) as starting points. These elements can be grouped as the goals, target groups and demarcation of policies, which we subdivide into a) the width (what is protected and what is not) and b) depth (to what extent is something protected); c) the means, rules, instruments or tools to provide protection with; d) time choices or duration of protection; and e) background, rationales and underlying assumptions, i.e. legitimation of policies. We link these dimensions to the two levels of learning in order to conceptualise protective policy measures about which the actors need to learn and which are part of their mutual deliberations.

\subsection{Five dimensions of protective policy measures}

The five dimensions of protective policy measures closely follow the differentiation between first- and second-order learning. First-order or instrumental learning relates to the understanding of the content of the policy measure itself. In the context of protection we translate the instrumental or technical aspects into width, depth, duration and tools of protection measures. Second-order learning relates to the underlying beliefs and the way in which problems are perceived and solutions are framed in the context of narratives. We interpret this as legitimising narratives of protection.

The first dimension relates to the selection of technologies that qualify for protection (Kemp et al. 1998). Dealing with emerging technologies, these selection processes are inherently uncertain and there is always the dilemma between inclusiveness versus focus of a portfolio of options. We refer to this dimension as the width of protection provided. In other words: what is protected and what is not? As shielding typically concerns a portfolio of options, defining the width of protection is not so much a matter of picking winners, but rather a matter of dropping losers (Bakker et al. 2012). The second dimension relates to the extent to which protection is provided to technologies in the portfolio. We define this as the depth of protection. Depth of protection includes discussions about the evaluation criteria that define the degree of protection. In the literature this issue is mostly related to the question whether or not the emerging technologies depend too much on support and whether or not (public) resources are used efficiently (Hommels et al. 2007). Related to the depth of protection is a third dimension that emphasises the temporal character of niche protection: the duration of protection. Basically, niche protection is meant to be temporary and at some point the depth of protection needs to be reduced. The question, obviously, is when protection can be reduced 
or removed, which entails a balancing act. Protection may be removed too early leading to collapsing transition trajectories (Negro et al. 2012), whereas protection being removed too late may produce 'lazy' actors (Nill and Kemp 2009). Fourth, several tools can be employed to provide protection. These may range from $R \& D$ subsidies, to incentives for market development, to regulatory exemptions, etc. Different technologies or transition trajectories may call for different tools for protection and we expect that actors learn about the effectiveness, efficiency, and interplay of various tools (Wieczorek et al. 2009).

The final dimension, legitimisation of the protective policies, relates to the underlying mechanisms and narratives of the regulatory measures, i.e. to second-order learning. This dimension concerns questions like what is the narrative that supports the measures vis-à-vis other stakeholders and the general public?

In both of our case examples we will, next to a more generic storyline about the emergence of protective regulation, focus on these dimensions. We then ask: who learnt what regarding these five dimensions and how did these lessons affect negotiation processes?

\section{Methodology}

The empirical part of this paper revolves around two cases. First, the pharmaceutical sector in which regulation to a large extent dictates the speed and direction of innovation (Munos 2009; Scannell et al. 2012). We focus on regulatory pathways that protect the development of pharmaceutical products for diseases with high unmet medical needs, i.e. "needs that are not addressed adequately by an existing therapy” (FDA 2006), such as products for HIV, cancer, pandemic influenza and rare diseases. In the case of rare diseases, for example, protection is needed because there is no economic incentive to invest in these small markets. The orphan drug acts in the US and EU can be seen as protective measures to support drug development for rare diseases. These orphan drugs may be perceived as predecessors of tailor-made pharmaceutical innovations that potentially change the regime of drug development and as such lead to a transition to sustainable health care. Second, the automotive industry has relied on the internal combustion engine car over the last century, but nowadays is challenged to develop and commercialise much cleaner and ultimately zero-emission cars. The second case focuses on the development of electric vehicles and the protection provided to realise this potentially disruptive innovation. 
As was introduced in the first section, both cases are subject to high levels of regulation (Stewart 2010) and are concerned with unmet societal needs that are contested by a wide array of stakeholders. There are also differences: the pharmaceutical case is about regulation, whereas the automotive one concerns more supportive instruments. Covering such broad range of policy measures might have theoretical repercussions because they are part of different policy instrument categories, viz. regulative or 'stick' and allocative or 'carrot' measures (Dunn, 1994).

The case studies are the result of extensive studies of the pharmaceutical and automotive sector in the European context with an emphasis on the Netherlands (Boon et al. 2010; Bakker et al. 2012; Sierzchula et al. 2012a; Sierzchula et al. 2012b; Trip et al. 2012; Meijer et al. 2013; Bakker et al. 2014; Boon et al. 2014). These cases draw on previous (and partly published) research that is based on document research, workshops and in-depth interviews with actors inside and outside the niches, taking into account a wide and heterogonous range that aims to cover all relevant parties.

For the high-unmet needs drugs the data collection consisted of three steps. First, we conducted in-depth interviews with a wide array of stakeholders, including three members of the Dutch and European medicines evaluation board; one from the Healthcare Inspectorate; eight from pharmaceutical companies; one industry representative organisation; five representatives of patient organisations; one from the Dutch national reimbursement agency; five medical specialists who also lead research groups; one board member of the organisation that represents nurse practitioners; one person from the umbrella organisation for municipal health services; one from the Dutch representative organisation of pharmacists; one civil servant from the Dutch health ministry; two scientists who study the pharmaceutical sector; two medical ethicists; and six representatives of post-marketing surveillance centres. Interviews lasted for 60-75 minutes. The interview protocol consisted of three parts: 1) discussing the specific (conditional) marketing authorisation processes in which the respondent personally had been involved, including giving a historical account as well as evaluating these processes; 2) specifically discussing the (conditional) marketing authorisation process in terms of the stages of the innovation process (clinical trials, postmarketing phase, reimbursement); 3) discussing the interactions, roles and responsibilities of actors involved in the conditional marketing authorisation processes. Aim of these interviews was to uncover behavioural and attitudinal aspects of user innovations. The interviews were audiotaped and the outlines were subsequently transcribed and checked by the respondents. 
Second, document analysis was done with the purpose of obtaining an overview of the context and content of the projects. The major sources for these documents were threefold: 1) European legislation and legal background documents; 2) scientific journal articles about early-access schemes in the EU and US; 3) the European public assessment reports (EPARs) published for the medicinal product that obtained conditional marketing authorisation.

Third, we organised three workshops in which stakeholders, such as representatives from patient organisations, government, post-marketing bodies and medical specialists organisations reflected on the results of the study. These meetings lasted for about three hours and notes were taken.

For the electric vehicle case a combination of research methods was used. Data drawn from aforementioned studies were augmented with observations made at several workshops and roundtables where policymakers and stakeholders discussed and negotiated supportive policies for electric vehicles and their recharging infrastructure. The published studies made use of 38 interviews with key stakeholders (Bakker et al. 2014) and a Group Decision Room workshop with 7 municipal policymakers (Bakker and Trip 2013). The interviews were held with national and local policymakers and with representatives of the automotive industry, electricity suppliers, grid operators, oil companies, NGOs, and dedicated electric vehicle businesses who either supply charging equipment or charging services. These interviews were semi-structured and dealt with the actors' activities regarding electric mobility and their motivations to do so. Even though measures of protection were not the main subject of the interviews, all actors referred to such measures and commented on their effects on the transition trajectory and the (lack of) legitimisation of these measures. Anonymised interview reports were written for each interview and these were subsequently analysed. The Group Decision Room (GDR) workshop brought together municipal policymakers from five different European countries. All of these policymakers were directly responsible for electric mobility-related policies in their cities. Such policies are typically aimed at providing incentives for the adoption and use of electric vehicles in the urban environment. During the workshop, the participants were asked to list the policies that were implemented in their respective cities and to comment on their effectiveness, efficiency, and political feasibility. The anonymity provided by the GDR system enabled them to speak freely about their success and failures in supporting adoption of electric vehicles and hence to speak about the lessons learnt concerning these measures. 
The documents, interview transcripts and workshop reports were subsequently coded using a coding scheme that is based on the five dimensions of protective policies, which were introduced at the end of Section 2. Table 1 presents the way in which the five dimensions are measured, including the codes used and empirical examples of these codes.

Table 1: operationalisation of the five protection dimensions.

\begin{tabular}{|c|c|c|}
\hline Dimensions & Indicators/codes & Example statements \\
\hline Width & $\begin{array}{l}\text { Type of } \\
\text { products/class/sector to } \\
\text { which protection applies } \\
\text { (scope) }\end{array}$ & $\begin{array}{l}\text { "This regulation applies to the product } \\
\text { class }[\mathrm{X}] \text { and }[\mathrm{Y}] . . . "\end{array}$ \\
\hline Depth & $\begin{array}{l}\text { Level of protection } \\
\text { provided (extent) as } \\
\text { measured by evaluation } \\
\text { criteria }\end{array}$ & $\begin{array}{l}\text { "The scheme provides }[\mathrm{X}] \text { financial } \\
\text { support when the products fulfils criteria } \\
{[\mathrm{Y}] \text { ” }}\end{array}$ \\
\hline Duration & $\begin{array}{l}\text { Time period during } \\
\text { which protection is } \\
\text { maintained }\end{array}$ & $\begin{array}{l}\text { "The market exclusivity is valid for the } \\
\text { first } 20 \text { years after market introduction..." }\end{array}$ \\
\hline Tools & $\begin{array}{l}\text { Specific aspects of the } \\
\text { protective instrument } \\
\text { providing the protection }\end{array}$ & $\begin{array}{l}\text { "The enforcement of the regulation is } \\
\text { organised as follows..." }\end{array}$ \\
\hline Legitimisation & $\begin{array}{l}\text { Assumptions underlying } \\
\text { width, depth, etc. }\end{array}$ & $\begin{array}{l}\text { "The reasons for including product class } \\
{[\mathrm{X}] \text { are..." }}\end{array}$ \\
\hline
\end{tabular}

After this coding exercise, the statements and quotations pertaining to the same code (or dimension for that matter) are collected. This presents in-depth insight into the articulation of each dimension. The coded dimensions were then placed within the storyline or timeline of the cases, thus providing insights into the changes in perception about niche protection (measures), and as such indicating learning processes. The next Section presents this overview of the five dimensions for the two cases.

\section{Case analysis}




\subsection{Shielding high-need pharmaceuticals through accelerated approval schemes}

Drug innovation entails a set of activities that together are time- and resource-consuming, totalling on average 13 years of preclinical and clinical tests. In cases of an imminent health threat or unmet medical need there are calls for relaxing regular approval criteria. An unmet medical need is related to "a condition for which there exists no satisfactory method of diagnosis, prevention or treatment authorised in the Community or, even if such a method exists, in relation to which the medicinal product concerned will be of major therapeutic advantage to those affected” (Commission 2006). Legislators have attempted to deal with this balancing act between faster market access and rigidity of regulatory requirements.

\section{Width of protection}

The basis of regulating drugs for unmet medical needs was formed at the time of the HIV/AIDS epidemic in the 1980s, when the US government introduced regulations that stimulated accelerated approval. The European Union followed suit with a so-called 'approval under exceptional circumstances’ scheme to ensure market approval for drugs for which developers are unable "to provide comprehensive data on efficacy and safety under normal conditions of use because it is difficult [...] or unethical to obtain the data needed" (Council Regulation No 2309/93 art. 13). This regulation opened up the possibility to enter the market based on smaller datasets, which is beneficial to drug innovation for rare diseases; low prevalence makes it time-consuming to recruit a large number of patients to participate in clinical trials. In 2000 the EU introduced its orphan drug legislation, amongst others providing market exclusivity, protocol assistance and scientific advice.

In the early 2000s the European Commission aimed at broadening the accelerated approval scheme to include a wider range of disease areas. "The US regulations had been vigorously studied and translated to the European context” (interview result). During the translation, modifications were made which resulted into legislation that differed from the US. The special regulatory pathway was called ‘conditional market authorisation' and focussed on fast access to novel products, at the same time calling for rigid targets for post-marketing surveillance. Companies would need to commit to 'specific obligations' that were required to be fulfilled by conducting additional clinical trials. The scheme was open to pharmaceutical products that meet 'unmet medical needs' and that were in the interest of public health. The conditional market authorisation regulation thus expanded the width of the shield. Besides the drugs intended for rare diseases, i.e. orphan drugs, the categories include seriously- 
debilitating or life-threatening diseases, e.g. cancer and HIV, and medicines used in emergency situations, e.g. pandemic influenza (Commission 2006).

\section{Depth of protection}

During the implementation of the regulation, the European Medicines Agency (EMA) was dealing with two oncological products that seemed to meet the requirements of the conditional approval scheme. Civil servants responsible for the two dossiers thought that these products would form "easy test cases of the novel regulation” (interview result). This perception was based on their expectation that for both drugs promising clinical trial data were imminent. For one product, sunitinib, expectations were eventually met: several months after granting conditional approval, such data were produced. For the other product, gefitinib, EMA decided not to pursue the conditional approval route and to wait for additional trial data. Again, the decision proved to be favourable since the data were disappointing.

Despite the successful early experimentation and quick start, the EMA and companies were not satisfied. They perceived the novel regulation as "imposed on them" by the European Commission (interview result). They regarded the regulation as sketchy and in need of elaboration, which made involved stakeholders “confused” (interview result) about the depth of the shield provided. The Committee for Medicinal Products for Human Use (CHMP), which is the committee at the EMA responsible for preparing opinions on whether or not to license a medicinal products, thought "in all innocence" (interview result) that every real breakthrough therapy could be subject to conditional approval. Even if treatments showed no certain benefit/risk-ratio, but had promising perspectives. The committee's idea was that it could come to an agreement about the terms under which the confirmatory data would be delivered. If these clinical trials were not performed, then the product's license would be withdrawn; yearly reviews would audit the progress. EU solicitors, though, refuted CHMP’s view and underlined that the benefit/risk-ratio should be positive at all times. Their action brings the conditional approval scheme closer to the normal drug reviewing criteria, which makes it difficult for the CHMP to opt for the conditional approval route. Only in 2011 was the issue resolved after years of discussion between the legal departments of the EU and EMA. Although the process "remains a trial-and-error[one]. That is why some products are conditionally approved while afterwards the merit of this decision is less clear" (interview result). 
Besides the regulators, companies needed to learn about the depth of the conditional approval scheme. "The original EU scheme had the ambition to be close to the US accelerated approval programme. During discussing the legislation the EU, however, introduced small, nuanced differences that complicated adaptation of the rules for companies, most of which acted on and were acquainted with the US situation” (interview result).

\section{Duration of protection}

A wide variety of interview respondents discussed the duration of the protection measure in relation to the width of the shield, i.e. the disease areas covered. HIV/AIDS obviously was a life-threatening disease at the end of the last century but with the introduction of innovative medicines some respondents asked questions about the extent to which HIV/AIDS could still be regarded as a disease for which there is an unmet medical need, at least in Europe, and thus required protection: "the time that a medicinal product should enter the market very fast is over" (interview result). These signals even came from doctors and nurses specialised in HIV; according to them new medicines do not necessarily end up as front-line therapies at the top of the decision tree of medical guidelines.

On the level of specific products, discussions on continuation of protection also prevailed. Withdrawing protection appeared to be difficult in terms of emotional, financial, legal or political costs involved (Geva-May 2001). In the case of conditionally approved products these sentiments are precarious, because drugs aimed at meeting unmet medical needs are by definition the only ones in a particular disease area (interview result). Regulatory agencies facing the difficult decision to terminate a policy might feel the pressure coming from e.g. patient organisations. These so-called 'agenda-setting gatekeepers' are quite influential (Carpenter 2002) and try to 'capture' governmental agencies to proceed in line with their interests (Carpenter 2004).

\section{Tools of protection}

Members of the approval committee were struggling with the criteria they should apply, as the discussion on benefit/risk-ratios showed. The protection regulation tool needed operationalisation. Risks were, by definition, relatively large since the extent of clinical trials conducted is smaller than with regular approval procedures ${ }^{2}$, thus producing less data on

\footnotetext{
${ }^{2}$ Most of the times, companies are allowed to present phase II trial data (trials in a small set of patients, typically ranging from 100-300 participants) and skip the elaborate phase III trials (trials in a larger sample of often over 1000 patients).
} 
safety and efficacy. Not only are the clinical trials less extensive, the type of data is also less rigorous. Accelerated approvals often rely on surrogate endpoints ${ }^{3}$ instead of clinical endpoints to detect the clinical efficacy and safety. Critique on the validity of surrogate endpoints concerns a poorly understood correlation between surrogate and biological endpoints (Fleming 2005).

Next to development work on the inclusion criteria, there was also a need for additional tools related to data collection during the post-market phase. The underlying assumption of the scheme was that regulators and companies entered an agreement: in return for fast approval of products companies were supposed to address associated uncertainty and generate additional data. Regulators became dissatisfied with the lagging delivery of requested post-marketing data (interview result). Failing the completion, these products remained 'conditionally approved', in extremis even forever, which was far removed from the original idea of keeping this status as short as possible. The first case, sunitinib, had "neatly followed this line" (interview result). For other cases companies claimed to lack proper tools to turn the postmarketing clinical studies into randomised trials because it was deemed unethical to provide placebo products to seriously-ill patients (Dagher et al. 2004). "It is unethical to experiment on patients with the sole aim of obtaining a marketing authorisation” (Garattini and Bertele 2007).

Following the conditional approval regulation, failure to provide post-market data could lead to withdrawal of the product's licence. However, as was stated above, withdrawal of products is an exercise that is complex and might demand additional support tools. A US Government Accountability Office (GAO 2009) report states that the US drug regulator (FDA) had never withdrawn a product since the initiation of its accelerated approval programme in 1992. Even products that proved to insufficiently match safety and efficacy requirements were not pulled off the market. The GAO conclusions reiterate a point made by Roberts and colleagues (2004) who observed that the FDA had not taken action against drugs for which no additional data were provided, even when for only 6 of these 23 oncology-related products post-marketing trials were completed. The tools to exercise withdrawal are formally there, but "incentives for practical application seem to be missing" (interview result).

\section{Legitimisation of protection}

\footnotetext{
${ }^{3}$ Surrogate endpoints are indicators of the effect of a treatment instead of real clinical endpoints. Examples include progression-free-survival (oncology) and CD4 cell count (HIV). Especially applied with life-threatening diseases because the use of real endpoints, such as death, is undesirable.
} 
The above-treated dimensions signify the importance of two arguments underlying the conditional approval scheme. First, in the execution of the regulation, fast access to high-need medicines and safeguarding public health require to be balanced. The discussion about the duration of the scheme shows that the degree of unmet medical need can become contested. Also, safety of patients is still very much central to decisions made by regulators and companies, meaning that even if there is a clear need for a drug, safety issues will be taken seriously. Although severely-ill patients are often associated with strong demands for early access, this view is not shared by all patients according to a patient survey (Mayer 2006) due to fear for suboptimal quality of science and eventual of drugs (Epstein 1997). "Innovation, yes, we want drugs out there as quickly as possible. But it needs to be done safely. You will have to find a compromise somewhere" (interview result).

Second, legitimisation is very much subject to changing perceptions of affected stakeholders. For example, companies have become less enthusiastic about the conditional approval scheme because they re-evaluated the benefits and costs of the scheme. At first, they were pleased with the shorter time-to-market. Obtaining market access is a race against the clock; for 'blockbuster drugs' every additional day may yield several millions of euros. At the same time, the conditional approval scheme dictates investments in additional data collection after market introduction, these obligations being subject to yearly review. Besides extra work, such yearly review introduces a "sufficient degree of uncertainty about a product's market license and constant negotiations [between the regulatory affairs department and the board] to legitimise studies for a drug that is already on the market" (interview result). Moreover, in at least one case a pharmaceutical company obtained a conditionally-approved product encountered problems during the decision-making process regarding drug reimbursement. "That is where the trouble started; we never should have pursued that" (interview result). Because obtaining conditional approval means that companies can skip elaborate clinical phase III trials, they are also unable to collect sufficient data on efficacy and safety that should fuel the dossiers for reimbursement decisions. This led to the paradoxical situation that a drug had been granted early licensing but was still not available to patients.

Both discussions have not led to concrete changes in legislation, and thus to changes in protection measures. The developments on the legitimisation of protection are still undercurrents that are not well articulated and therefore do not trigger strong empowerment activities. Interestingly, these critical points are mostly raised by insiders, such as companies and medical specialists, or affected actors, such as patients. This has something to do with the 
fact that there are no outsiders that have strong, antagonistic viewpoints vis-à-vis the protection measures, making empowerment activities less imperative.

In conclusion, the process of trial-and-error learning by regulators and companies about how to use the conditional approval legislation has been going on since its introduction. Both companies and regulators needed to become acquainted with the regulation: "there was nothing specified", it was an "exploratory exercise", "we all had to learn", "what is specified?" (interview results). Although experimentation had produced clear ideas about how to implement the regulation, the subsequent period showed negotiations and discussions about the width and depth of the scheme. In addition to the first-order learning, there have been albeit subdued - deliberations about the legitimisation of the protection measure.

\subsection{Shielding clean cars: battery electric vehicles}

The introduction of electric vehicles (EVs) offers opportunities for a wide variety of actors, including national and local governments, energy producers, electricity grid operators, car manufacturers and importers, and a variety of NGOs. Legitimised by concerns over climate change, local air quality, security of energy supply, and supported by ideas about green growth, governments worldwide have provided protection for the development of low- and zero-emission vehicles since the late 2010s (Bakker et al. 2014). Under this umbrella, various technological options have been developed (Bakker et al. 2012; Sierzchula et al. 2012a). The options include biofuel and natural gas powered combustion engine vehicles, (plug-in) hybrid and full electric vehicles, and hydrogen powered fuel cell vehicles. Shielding for these options has predominantly been provided by policy measures that forced the automotive industry to develop the enabling technologies and bring these vehicles to market. Well-known examples of such regulations include the US CAFE fuel efficiency standards, the Californian Zero Emission Vehicle mandate, and, more recently, European carbon emission norms.

\section{Width of protection}

The introduced EU policies are by and large technology neutral since they are defined in terms of a passenger car's energy efficiency or emission levels of certain pollutants and not in terms of specific technological solutions. The scope of protection is not explicitly defined in terms of included and excluded technological options. Rather, the width of protection is implicated by emission thresholds which allow some technologies and rule out others. Moreover, governments have provided resources for R\&D and all sorts of pilot projects and 
infrastructure build-up. Such protection measures are necessarily geared towards specific technologies and policymakers then have to decide on the width of protection in more explicit terms, e.g. proposing research programs for batteries and fuel cells, not for biofuel production. The global automotive industry has welcomed funds for research, but has consistently fought all too strict regulations on emissions and efficiency, especially those which are explicitly technology specific (Wesseling et al. 2014; Wells and Nieuwenhuis 2012).

On the national and local level, governments also provide shielding for clean cars. To some extent these shielding measures are meant to be technology neutral, e.g. based on emission levels, but in practice they imply specific choices for technological options. In the Netherlands such measures were available for all plug-in electric vehicles, including plug-in hybrids such as the Opel Ampera and the Mitsubishi Outlander. In line with European norms, the Dutch government has defined a threshold for low-emission vehicles at 50 grams of $\mathrm{CO}_{2}$ per kilometre; all cars which emit less carbon qualify for protection in the form of tax exemptions (EZ 2011). This is quite different from countries like Denmark and Norway, where protection is exclusively available for full-electric (zero-emission) vehicles. According to a senior policy maker, this choice relates strongly to the timing of the policy making process: "in the Netherlands we have set these fiscal rules when there was no plug-in hybrid on the market. The technology was being discussed and we recognised the potential [of plugin hybrids] as a transitioning vehicle [...] There was no fiscal differentiation between EVs and PHEVs, also because it was felt that both were needed [...] The Norwegian policy is older and they never even considered anything but full-electric [because PHEVs were not in the picture yet]" (interview result).

From the start, the Dutch solution has been questioned by several stakeholders (e.g. car manufacturers offering full-EVs) as to whether these measures should indeed cover all the options. Furthermore, car leasing firms and charging service providers have repeatedly warned, for instance during the national EV symposium in 2013, that PHEVs were used improperly, i.e. driving too little kilometres in electric mode, which would reduce the effectiveness of public support schemes. From 2014 onwards, tax benefits are more favourable for the full-electric models. Such a differentiation is better aligned with policy goals that currently state that full-EVs should make up 30\% of the plug-in car mix by 2020.

Depth of protection 
On a national level, EVs in the Netherlands were exempt from registration tax for vehicles, yearly road use taxes, and income tax paid for the private use of company cars (so-called 'bijtelling'). Also, for businesses, additional tax deductions for green investments were opened up to EVs. Together these incentives have made the Netherlands one of the most favourable countries for EVs and it is thus no wonder that car manufacturers were eager to bring relatively large numbers of their electric vehicle models to the Dutch market. The resulting market share of EVs is correspondingly high as compared to other countries (Sierzchula et al. 2014). The value of these incentives has been subject to much contestation. For policy makers it has proven difficult to assess a priori which value is most effective and efficient. As one of the, non-Dutch workshop participants remarked: "Subsidies for cars have not proven so popular because they still do not reduce the cost of an EV to that of a comparable ICE vehicle. The risk is also that manufacturers inflate their prices in line with the subsidy" (interview result).

Most of all, the costs of financial incentives providing shielding increase linearly with adoption rates achieved through those stimuli. In fact, the incentives were so favourable, especially for company car drivers, that demand for PHEVs exceeded supply and cumulative sales figures were 1.5 years ahead of the policy targets. In 2014, a study commissioned by the Dutch government showed that in the years 2012 and 2013, when support for EVs was at maximum depth, tax incentives for PHEVs (698m) and full EVs (75m) cost a total of 773 million Euro (Kok et al. 2014). With 3037 full-EVs and 24495 PHEVs sold in these years ${ }^{4}$, public support amounted to 24.7k Euro on average for a full-EV and 28.5k Euro for a PHEV. The evaluation report concludes that these amounts have resulted in far too high costs per ton of avoided $\mathrm{CO}_{2}$ emissions. More importantly, from a transitions perspective, it concludes that PHEV subsidies were simply too high and that similar sales figures could have been achieved with lower levels of subsidy. The Dutch automotive sector initially supported the high-value incentives, but it also has learnt about the unintended consequences. As noted by a representative: "nobody had foreseen that it would go this fast" and "we are currently lobbying for a less rigorous system" ${ }^{5}$. To the dismay of the sector, the specific support for (PH)EVs resulted in a disturbed market in which Mitsubishi, Opel, and Volvo were the only manufacturers that really profited from the subsidies. From a policy perspective, the success

\footnotetext{
${ }^{4}$ http://www.rvo.nl/onderwerpen/duurzaam-ondernemen/energie-en-milieu-innovaties/elektrisch-rijden/standvan-zaken/cijfers, last visited on 30 March 2015, SPECIAL Personenauto’s Uitgelicht: Opkomst van range extenders en plug-ins, Agentschap NL, oktober 2012.

${ }^{5}$ Stekkerauto kost fiscus half miljard, de Volkskrant, 29 March 2014.
} 
of the measure was also a surprise: "it all went much quicker than we could have dreamt" (interview result). Even though the PHEV sales figures did not really tally with policy goals, PHEV vehicles did "contribute to the rollout of the charging infrastructure and many companies being able to make a living out of electric mobility” (interview result).

Also in the city of Amsterdam, high-value support for EVs was reduced in 2011 after a new alderman (a liberal) had called for an evaluation of the cost-effectiveness of the measures taken by his (green-party) predecessor. It became clear that support for electric (private) passenger cars was among the most expensive (i.e. least efficient) measures to reduce air pollution and that better value for money could be achieved through support for electric taxis and cleaner heavy duty vehicles ${ }^{6}$.

\section{Duration of protection}

The early success of the shielding measure came at too high a cost and some of the tax benefits were reduced from 2014 onwards. The reduction of incentives led to a run on dealerships towards the end of 2013 as many prospective (PH)EV drivers wanted to register their cars in 2013 to receive the full package of incentives. In contrast, the early months of 2014 showed rather low sales of all plug-in cars, but since the second quarter sales have picked up again (Figure 1). The sales figures also show, from 2011 onwards, a strong divergence between full-EVs and PHEVs, with full-EVs falling behind ${ }^{7}$ (Figure 2). One car importer anticipated these dynamics when he complained that Dutch resources were spent too fast on the first generation of EVs and that it would have been better to save some funds for subsequent generations, thereby creating a more stable market environment. Next to this general concern, he was also worried about selling 'his' EVs which were still to be delivered to the Dutch market (interview result).

\footnotetext{
${ }^{6}$ Einde aan symboolpolitiek, Het Parool, 18 May 2011.

${ }^{7}$ http://www.rvo.nl/onderwerpen/duurzaam-ondernemen/energie-en-milieu-innovaties/elektrisch-rijden/standvan-zaken/cijfers.
} 


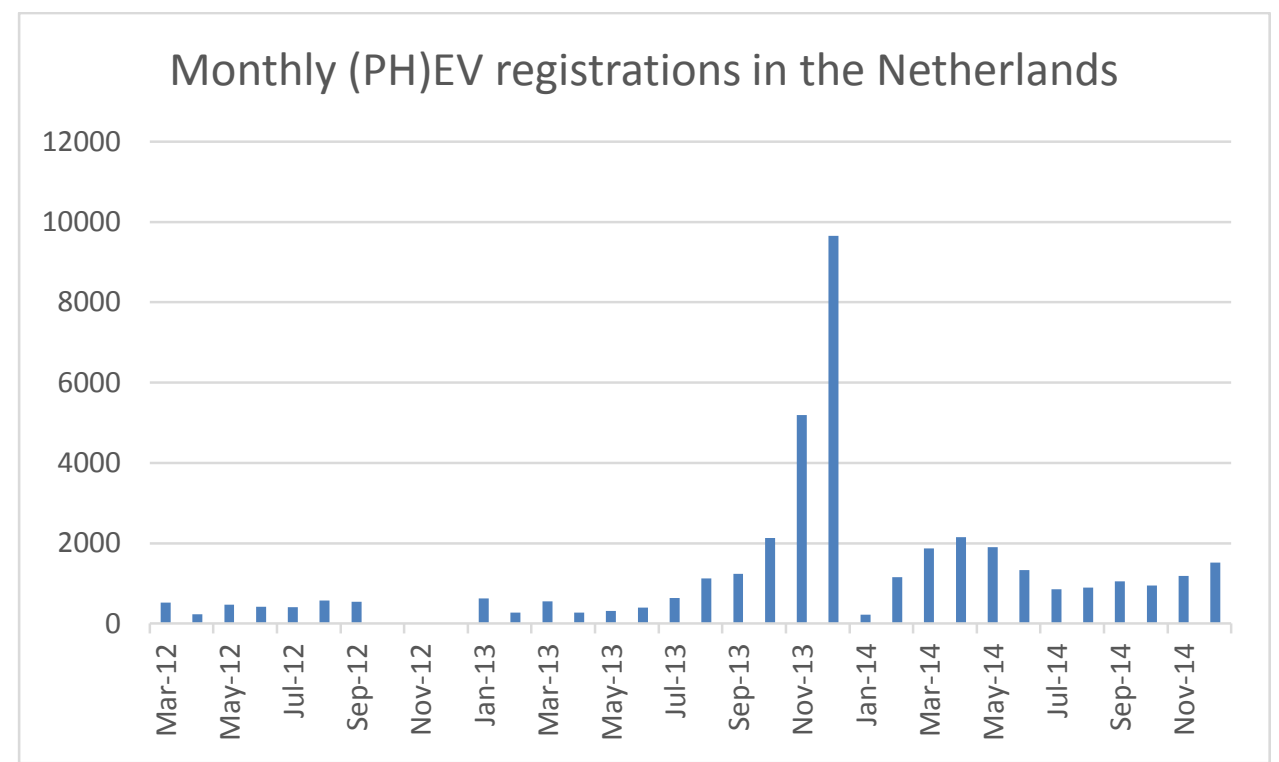

Figure 1: Monthly new (PH)EV registrations in the Netherlands (data from October December 2012 is missing).

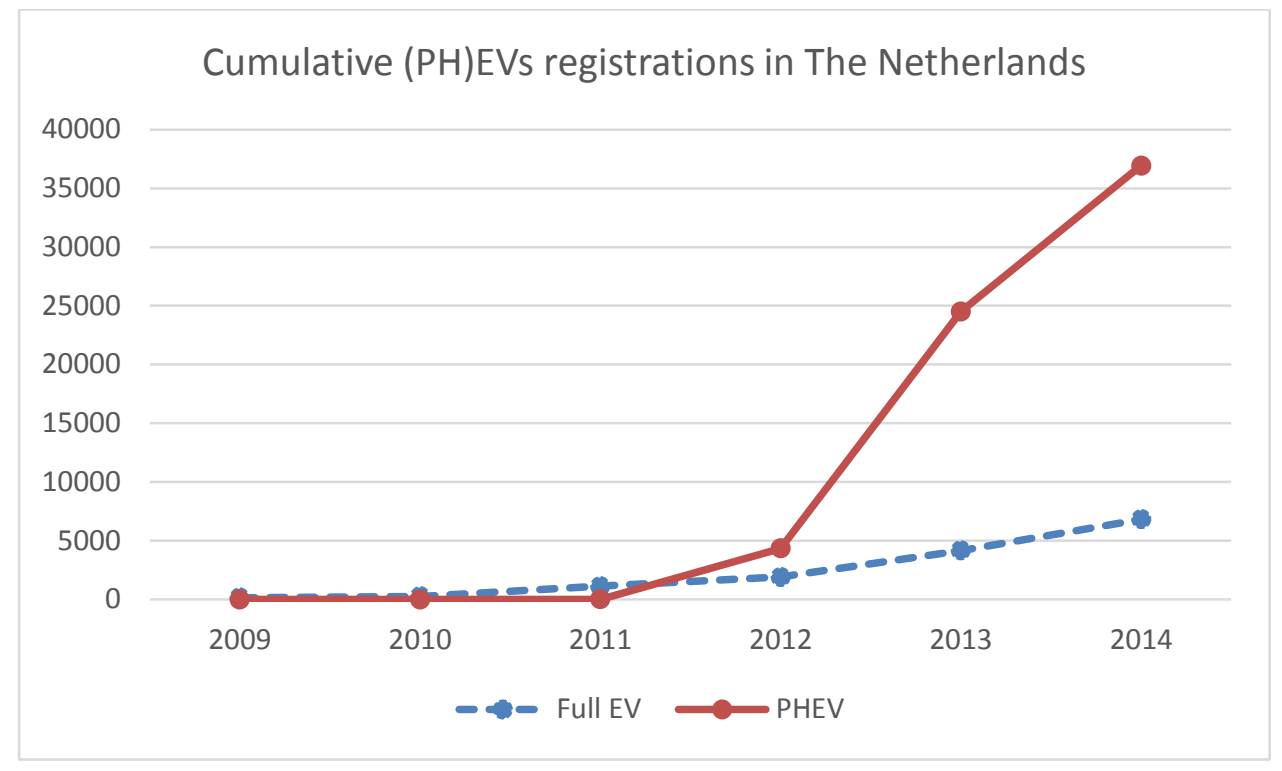

Figure 2: Cumulative registrations of full-EVs and PHEVs in the Netherlands.

The reduction of incentives, and likewise a further reduction which was announced by the end of 2014, was not welcomed by most stakeholders as they feared that it would kill the momentum for EVs. In November 2014, a broad coalition of automotive companies, car leasing firms, entrepreneurs' organisations, and environmental organisations lobbied heavily to retain some of the tax incentives for $(\mathrm{PH}) \mathrm{EV}$ s and to a lesser extent other environmentally 
friendly cars. Their proposal, as adopted by the State Secretary for Finance, also included a further differentiation between EVs and PHEVs. The differentiation was meant to create a more equal balance in sales between the two vehicle types.

\section{Tools of protection}

Protection is not only provided by direct financial support for vehicles. The funding, regulation, and standardisation of a recharging infrastructure have also proven valuable, and according to policy makers have contributed to the Dutch successes regarding EVs. Whereas EV drivers ideally charge their cars at home during the night and possibly during the day at their offices, many drivers do not have such possibilities and thus need to rely on charging spots in public space. In addition, chargers are needed for ad-hoc charging during trips. Even though the ad-hoc charging spots may not be used frequently, their presence is deemed necessary to comfort EV drivers and reduce their so-called 'range anxiety'. Initially, since 2010, many of these charging spots in public space have been installed by electricity grid operators. They did so for several reasons, most importantly because they wanted to learn about the EV transition and to remain in control of the additional grid load resulting from charging EVs (Bakker 2014). These stations, together with the hundreds of chargers that were installed on behalf of the four largest cities in the Netherlands, form the backbone of the public recharging infrastructure. However welcome their activities were to the EV niche, the Ministry of Economic Affairs decided that the grid operators were no longer allowed to invest in charging spots from 2013 onwards. The Ministry ruled that the operators had acted beyond their mandate and that their initiatives hindered the emergence of a commercial market for EV recharging. In other words, learning took place regarding the tools for protection; semi-public investments by grid operators were not acceptable from a market-development perspective.

Because private actors did not take over the role of the grid operators, the focus for infrastructure realisation shifted completely to the provision of close-to-home chargers for EV drivers who relied on on-street parking and charging. Such chargers were provided by large cities (Amsterdam, Rotterdam, and Utrecht) and, albeit in lesser numbers, by other regional and local authorities.

Next to offering public chargers, cities also provided free parking for EVs as an additional consumer incentive. Policy makers have however learnt that the combination of parking and charging incentives may be counterproductive as charging stations get blocked by noncharging, free-parking EVs. As noted by one of the GDR workshop participants: "it is 
important to consider if your primary goal is to provide parking spaces for EVs or charging spaces for EVs. Almost 50\% of our EVs park at charging spaces but do not charge [they charge at home]" (workshop result).

The Netherlands, just like several other countries, have made an attempt to organise collective procurement of EVs by public authorities and companies. This type of policy tool has however proven unpractical because of all the constraints that come with public procurement procedures: "procurements can be difficult, time-consuming and expensive, and you may end up with a product you are not happy with” (interview result).

\section{Legitimisation of protection}

As noted, legitimisation of protection for plug-in cars is mostly based on environmental arguments. At the same time, economic growth has been an important issue as well as the enabling role EVs could play in the future (sustainable) energy system. On the basis of the latter arguments, the main responsibility for EV-related policies has shifted early on from the Ministry of Environment to Economic Affairs.

Sources of legitimacy differ between levels of government. At the national level, air quality is currently considered the least important argument (interview result), but concerns over local air quality and the direct health risks it poses are very important in affected cities. Hence, the largest cities in the Netherlands were facing severe penalties, e.g. a halt on urban development projects, for not meeting European norms for air quality. These worries resulted in a governmental fund that could be used to finance all sorts of air-quality improvement measures at the local level. The largest cities, for which most of the funds were meant, chose to, among others, provide local subsidies for vehicles and the aforementioned charging stations. The high demand for on-street chargers is directly related to the initial decision to treat fullelectric and plug-in hybrid vehicles equally. Many of the PHEV drivers do not have private parking facilities and would use their PHEVs mostly as conventional gasoline cars if it was not for public charging stations ${ }^{8}$. In other words, the depth and especially the width of protection ultimately threatened the legitimacy of these measures and additional measures (i.e. publicly financed charging stations) were needed to solve the problem.

\footnotetext{
${ }^{8}$ In most cases fuel costs are paid for by the drivers' employers and there is thus no direct incentive for drivers to save on conventional fuel costs. Even more so, there is an incentive not to charge cars (at home) because it is more difficult to get the additional electricity costs reimbursed. The notion of 'free gasoline' is so deeply rooted in this lease car culture that even some full-electric vehicles were delivered with a 'fuel card'.
} 
In conclusion, the Dutch government, local authorities, and other stakeholders have struggled with the costs and duration of shielding. At any time the support for all types of plug-in vehicles was contested and to increase the legitimacy of this decision it proved necessary to seek ways in which PHEV drivers could be persuaded to actually charge their cars instead of simply using them as regular gasoline cars.

\section{Conclusions and discussion}

\subsection{Conclusions}

In this paper we set out to study the process of policy learning in the context of protection of technological niches. To do so, we introduced five dimensions of niche protection which can be subject to learning. The dimensions included (first-order) learning dimensions about the content of regulation, e.g. about the width (what is protected?), depth (the extent to which protection is provided and hence the costs of protection), duration of protection, and the various tools to provide protection with. Moreover, we found that (second-order) learning about the legitimisation of the protection takes place. That is, actors learn about the most effective and politically sustainable arguments for protection.

In answering the question how policy learning shapes protective spaces, the two cases show that learning about protection policy measures goes hand in hand with the process of negotiation between stakeholders in the early stages of a transition. Stakeholders need to learn what protection may entail and how protection measures are best implemented. Part of the learning process also relates to the question what the effects of the policies are on themselves, on other stakeholders and on the transition pathway as such. Learning applies to a wide array of actors active in the niche, ranging from regulators and pharmaceutical companies to infrastructure providers and car manufacturers, as well as outside the niche. 
Table 2: Dimensions of policy learning in the high-need pharmaceutical and electric vehicle sectors.

\begin{tabular}{|c|c|c|}
\hline & $\begin{array}{l}\text { Protection of medicines for unmet } \\
\text { medical needs }\end{array}$ & Protection of battery electric vehicles \\
\hline \multicolumn{3}{|c|}{ First-order learning } \\
\hline Width & $\begin{array}{l}\text { Scope of the accelerated schemes was } \\
\text { widened; not only including rare } \\
\text { diseases but also explicitly-defined } \\
\text { categories for life-threatening diseases } \\
\text { and emergency health risks. }\end{array}$ & $\begin{array}{l}\text { Supposedly technology neutral norms } \\
\text { define width of protection and thus } \\
\text { imply technology selection. Inclusion of } \\
\text { PHEVs has led to adoption rates } \\
\text { exceeding expectations by far and } \\
\text { further differentiation between options } \\
\text { proved necessary and effective. }\end{array}$ \\
\hline Depth & $\begin{array}{l}\text { Precise elaboration of the scheme was } \\
\text { not clear for regulators and companies. } \\
\text { E.g. criteria like benefit/risk-ratio } \\
\text { needed definition. }\end{array}$ & $\begin{array}{l}\text { Value of incentives to trigger }(\mathrm{PH}) \mathrm{EV} \\
\text { adoption led to adoption rates exceeding } \\
\text { expectations. This created a need for } \\
\text { additional protective measures to } \\
\text { facilitate charging these cars on-street. }\end{array}$ \\
\hline Duration & $\begin{array}{l}\text { Withdrawal of protection of individual } \\
\text { medicines is difficult because of } \\
\text { political pressure. Changes in } \\
\text { perception of the need for protecting } \\
\text { entire disease areas. }\end{array}$ & $\begin{array}{l}\text { Tension between success of measures } \\
\text { and rising costs led to early reduction of } \\
\text { incentives. Feared backlash from } \\
\text { reduction of protection was only } \\
\text { temporarily. }\end{array}$ \\
\hline Tools & $\begin{array}{l}\text { Operationalisation of scheme was } \\
\text { difficult because tools were ill-defined } \\
\text { (benefit-risk ratio) or not sufficient } \\
\text { (e.g. policy termination). }\end{array}$ & $\begin{array}{l}\text { Financial and non-financial measures, } \\
\text { but struggle over stakeholder roles and } \\
\text { distribution of costs. Uncertainty about } \\
\text { interplay of various policies. }\end{array}$ \\
\hline \multicolumn{3}{|c|}{ Second-order learning } \\
\hline $\begin{array}{l}\text { Legitimisation } \\
\text { of protection }\end{array}$ & $\begin{array}{l}\text { Balancing act between need for fast } \\
\text { and safe access to medicines is under } \\
\text { debate. Directly-benefiting parties are } \\
\text { not sure about gains of the scheme. }\end{array}$ & $\begin{array}{l}\text { General agreement on sustainability, } \\
\text { acute air quality problems, green (local) } \\
\text { growth. Unexpected adoption behaviour } \\
\text { of PHEVs challenged legitimacy of } \\
\text { protection. }\end{array}$ \\
\hline
\end{tabular}


In terms of the five dimensions, we have witnessed how lessons learnt led to either widening (to allow more actors to profit from the protection) or narrowing (because of limited resources and to realign with policy goals) of the width protection. The depth of protection was made more explicit, in the pharmaceutical case to provide clarity to stakeholders as to what they could expect from the protection. In the EV case, the depth of protection was mostly adjusted for financial reasons. In both cases, it was politically difficult to end or reduce the protective policies because of pressure from stakeholders, even though policies were always intended to be temporary. Before and during the implementation of the protective measures, stakeholders have struggled over the optimal mix of policy tools and new tools have been 'invented' during the process (i.e. a 'green deal' for public-private partnership to realise a public recharging infrastructure for EVs). Finally, both cases have seen struggles over legitimacy of the protective measures; in the medicines case the struggle was mostly inside the niche, while the EV case was much more subject to a wider public debate. Table 2 summarises the main findings for the respective dimensions from both cases.

\subsection{Reflections on policy learning for protection}

Based on the conclusions, our case studies also invite reflections on policy learning for niche protection. The reflections are treated following four questions.

First, who provides protection and what (or who) is protected? The analysis of the two cases showed the heterogeneity of actors influencing the width and depth of protection. A priori, one would assume that niche insiders are the primary actors engaged in protection. However, small niche actors typically only have proofs of concept of their innovative solution and a compelling story to offer, whereas protection is resource-intensive, e.g. involving subsidies or regulatory measures. Niche players cannot protect themselves and have to rely on powerful and wealthy actors outside the niche, e.g. those who are part of the existing regime. These regime players seem to initiate protection based on legitimising visions, such as propagating drug innovation for urgent health needs or clean driving leading to healthy cities. As such they act towards publics inside (pharmaceutical companies) as well as outside the niche (European legislators). Protection requires sufficient knowledge about niche activities and thus cognitive proximity, which merits the question to what extent niche outsiders really exist. In the pharmaceutical case we have witnessed how the European Commission acted as such an outsider, but at the same time one should also take into account that the Commission is at the core of the regime for drug approval. Moreover, having concluded that protective spaces 
are created jointly between the niche actors and regime-level players, both cases may be regarded as representing 'fit and conform' regime shift. Creating niche protection may be more difficult in cases of more radical, truly transitionary 'stretch and transform' regime changing (Smith and Raven 2012).

Second, what are the boundaries to the niche? Protection in terms of policy measures can be applied to different levels of aggregation, i.e. a nested hierarchy of technological niches. In the car case there is, for example, a staircase of steps from 'sustainable mobility' to 'clean cars' to specific technological options, such as the battery electric vehicle, and further down to the individual enabling technologies, such as batteries or fuel cells. In the context of pharmaceutical products, steps range from 'unmet medical needs in general' via disease areas, such as cancer, to specific pharmaceutical products, such as sunitinib. Descending to lower levels of aggregation serves as a way to test the execution of policy: using rules in specific situations provides lessons for future application in other contexts. For example, lessons learnt from regulating a specific drug is translated to higher ('global') aggregation levels as became apparent in clarifying specific evaluation criteria of the accelerated regulation. At the same time, more is learnt about the context-specific ('local') implementation of these policies, e.g. in different disease areas (Boon et al. 2014). Also, the level of protection has consequences for its legitimation. Given the ‘elusive quest for technology neutral policies’ (Azar and Sandén 2011), the appearance of technology-neutrality is maintained best at high levels of aggregation. The further one goes down the staircase in providing protection, the closer one gets to interference in industries and markets and the further one is removed from the 'level playing field' which is regarded as a beneficial consequence of innovation policy. This is evident in the pharmaceutical case in which protection for a specific, proprietary drug would automatically lead to protection for the company producing that drug. Still, even at the higher levels of aggregation (e.g. clean cars), technology-neutrality is probably just a mirage, e.g. 'neutral' protection based on carbon emission levels still implies the positive selection of a specific set of technologies.

Third, what is inside and what is outside the niche and, even more so, who are inside and who are outside the protective space? In our cases we show that niche insiders and outsiders interact about policies. Here, we discern between two types of interactions: 1) policymakers pour policies out over the niche, delegating to the stakeholders the way in which policies should be read and filled out; 2) policymakers and the regulated together deliberate on (and even negotiate about) the contents of policy. The first type, delegation of policy, implies that 
policies need to be developed and operationalised. This calls for a resource-intensive learning exercise that some stakeholders have problems to engage in. Reasons are that some stakeholders were not involved in setting up the protection measures or simply did not have sufficient resources to comply, apply or enforce (financial and/or cognitive) measures. The pharmaceutical case, for instance, shows that the CHMP needed to comply to and become acquainted with new regulations, during implementation. A last reason why stakeholders find it difficult to engage in learning about protection is that protection measures are part of a constant political/empowerment enterprise. This means that narratives and anti-narratives aim to 'explain' the niche protection measures differently, leading e.g. a regulatory agency to become 'captured' by interests of specific actors because they hold power over the agency (Carpenter, 2004). The automotive industry also proved to be sensitive to empowerment activities in all car-related policy making. The Dutch case shows that the industry has a positive interest in support for EVs, but tends to fight policies that favour a selection of manufacturers over the rest. In these dynamics there is a fine line between the politics of transitions, and hence of niche protection, and the related specific negotiations between actors on the one hand, and the process of learning about protective measures on the other. In other words, we need to be able to distinguish mere politics from instances of actors actually learning about the effects of various measures.

Fourth, to what extent is policy learning reflexive? As we mentioned in treating the previous reflection points, the (second-order) legitimisation of niche protection forms the basis of (first-order) dimensions. For example, the wish to maximally benefit healthy environments or disease areas that need new cures determines the choice for the width and depth of policies. At the same time, the narratives which reflect this legitimisation are in flux, and the cases show that they are influenced by developments in the first-order dimensions. Air quality, for instance, is a major driver for EV policies in larger cities, but as soon as European norms are met, policy priorities are likely to shift. Because of this, EV proponents within government, the relevant project teams within the ministry of Economic Affairs but also in the environmental ministry, now argue more strongly than ever that EVs are also important from an economic perspective.

\subsection{Discussion}

We would like to point out that these four lessons are conditional to the sectors under study. Related to this, for both cases one can question to what extent an actual transition is in the 
making. The development of high-unmet need drugs may be a precursor to broader changes in the pharmaceutical industry and mainstream regulatory processes, but the specific regulatory approach for these drugs may also remain the exception rather than the rule. The same goes for electric vehicles: although they present a radical innovation on the product level, e.g. a radically different way of propelling a vehicle, they do not necessarily lead to a novel transport system in which altogether different modes of transport are dominant. One could, from this perspective and as has already been mentioned in Section 5.2, say that both cases may turn out to be cases of 'fit and conform' instead of 'stretch and transform' regime changing (Smith and Raven 2012). Looking at the main actors involved, the former seems more likely, i.e. incumbent actors are at the forefront of the movements in both cases. At the same time, both industries are confronted with the absolute need to rethink core technologies (e.g. fossil fuel powered internal combustion engines) and business models (e.g. high-volume versus personalised drugs) and the initial steps described in our case studies may eventually trigger a veritable transition.

In conclusion, we aimed to contribute to conceptualising niche protection with the notion of policy learning. After niche protection is installed or agreed upon, a comprehensive learning exercise takes place, in which niche insiders (and outsiders) need to engage. Learning is required because several dimensions of policy often still need to be articulated. This conceptualisation of understanding and developing policy over time is essential because it shows that learning is an activity in which stakeholders ought to invest. Such learning about protection relates to previous literature on policy learning, aiming to include both trial-anderror learning and developing underlying norms and values that stakeholders have (Sabatier 1993; Grin and van de Graaf 1996). By this, the responsibility of articulating policy is distributed over cognitive and normative activities (e.g. empowerment), and over niche insiders and outsiders. The sustainability of policies is subject to political changes, limited resources or changes in narratives that uphold niche protection. Literature concerned with socio-technical transitions has often concluded that instable policies were to blame for the failure or slow pace of sustainability transitions (Negro et al. 2012). Our cases show that policymakers are not the only one to blame, since policy making is an interactive process of negotiations and, perhaps most of all, of learning between niche insiders and outsiders. Furthermore, we have shown that there are other relevant dimensions to policy measures than just their duration. Still, frequent and unexpected changes to protection measures may lead to insufficient learning and, eventually, less efficiency gains. This might result in innovation 
policy and niche protection being 'drifting' or inconsistent. Our message is that effects of policies cannot be predicted and, even more so, that the responsibility for policy drifting does not solely lie with governments. 


\section{Acknowledgments}

This research was supported by the Netherlands Organisation for Scientific Research (NWO) through its 'Responsible Innovation' and 'Sustainable Accessibility of the Randstad' programmes. The authors want to thank the reviewers and all participants of the Workshop 'Constructing and contesting spaces for low-carbon energy innovation' held in November 2013 in Eindhoven for their valuable comments.

\section{References}

Ambec, S., M. A. Cohen, S. Elgie, and P. Lanoie. 2013. “The Porter Hypothesis at 20: Can Environmental Regulation Enhance Innovation and Competitiveness?” Review of Environmental Economics and Policy 7 (1): 2-22. doi:10.1093/reep/res016.

Argyris, C, and D Schon. 1978. “Organizational Learning: A Theory of Action Approach.” Reading, MA: Addision Wesley.

Azar, Christian, and Björn A Sandén. 2011. "The Elusive Quest for Technology-Neutral Policies.” Environmental Innovation and Societal Transitions 1: 135-39.

Bakker, Sjoerd. 2014. "Actor Rationales in Sustainability Transitions - Interests and Expectations Regarding Electric Vehicle Recharging.” Environmental Innovation and Societal Transitions, September. doi:10.1016/j.eist.2014.08.002.

Bakker, Sjoerd, Kees Maat, and Bert Van Wee. 2014. "Stakeholders Expectations, Interests, and Strategies Regarding the Development and Implementation of Electric Vehicles.” Transportation Research Part A 66: 52-64.

Bakker, Sjoerd, and Jan Jacob Trip. 2013. "Policy Options to Support the Adoption of Electric Vehicles in the Urban Environment.” Transportation Research Part D: Transport and Environment 25: 18-23.

Bakker, Sjoerd, Harro van Lente, and Remko Engels. 2012. “Competition in a Technological Niche: The Cars of the Future.” Technology Analysis \& Strategic Management 24 (5): 421-34.

Bakker, Sjoerd, Harro van Lente, and Marius T H Meeus. 2012. “Credible Expectations - The US Department of Energy's Hydrogen Program as Enactor and Selector of Hydrogen Technologies.” Technological Forecasting and Social Change 79 (6): 1059-71.

Bennett, CJ, and M Howlett. 1992. "The Lessons of Learning: Reconciling Theories of Policy Learning and Policy Change.” Policy Sciences.

Blind, K. 2012. The Impact of Regulation on Innovation. Manchester.

Boon, Wouter P.C., Ellen H.M. Moors, Albert J. Meijer, and Huub Schellekens. 2010. "Conditional approval and approval under exceptional circumstances as regulatory instruments for stimulating 
responsible drug innovation in Europe. " Clinical Pharmacology \& Therapeutics 88 (6): 848853.

Boon, Wouter P.C., Ellen H.M. Moors, and Albert J. Meijer. 2014. "Exploring Dynamics and Strategies of Niche Protection.” Research Policy 43 (4): 792-803. doi:10.1016/j.respol.2014.01.005.

Cajaiba-Santana, Giovany. 2014. "Social Innovation: Moving the Field Forward. A Conceptual Framework.” Technological Forecasting and Social Change 82 (February): 42-51. doi:10.1016/j.techfore.2013.05.008.

Carpenter, Daniel P. 2002. “Groups, the Media, Agency Waiting Costs, and FDA Drug Approval.” American Journal of Political Science 46: 490-505.

2004. "Protection without Capture: Product Approval by a Politically Responsive, Learning Regulator.” American Political Science Review 98: 613-31.

Chappin, Maryse M.H. 2008. Opening the Black Box of Environmental Innovation: Governmental Policy and Learning in the Dutch Paper and Board Industry. Utrecht: Utrecht University.

Commission, European. 2006. Commission Regulation (EC) No. 507/2006 . Official Journal of the European Union, .

Dagher, Ramzi, John Johnson, Grant Williams, Patricia Keegan, and Richard Pazdur. 2004. "Accelerated Approval of Oncology Products: A Decade of Experience.” Journal of the National Cancer Institute 96: 1500-1509.

Dunn, William N. 1994. Public Policy Analysis: An Introduction. Englewood Cliffs, NJ: Prentice Hall.

Epstein, S. 1997. "Activism, Drug Regulation, and the Politics of Therapeutic Evaluation in the AIDS Era: A Case Study of ddC and theSurrogate Markers’ Debate.” Social Studies of Science.

EZ, Ministers van V\&W en. 2011. Elektrisch Rijden in de Versnelling - Plan van Aanpak Elektrisch Vervoer 2011-2015.

FDA. 2006. Guidance for Industry Fast Track Drug Development Programs - Designation, Development, and Application Review. Rockville.

Fleming, Thomas R. 2005. “Surrogate Endpoints and FDA's Accelerated Approval Process.” Health Affairs (Project Hope) 24 (1): 67-78. doi:10.1377/hlthaff.24.1.67.

GAO. 2009. New Drug Approval-FDA Needs to Enhance Its Oversight of Drugs Approved on the Basis of Surrogate Endpoints. Edited by U S Government Accountability Office. Washington.

Garattini, Silvio, and Vittorio Bertele. 2007. "How Can We Regulate Medicines Better?” BMJ (Clinical Research Ed.) 335 (7624): 803-5. doi:10.1136/bmj.39281.615706.94.

Garud, R, and D Ahlstrom. 1997. “Technology Assessment: A Socio-Cognitive Perspective.” Journal of Engineering and Technology Management 14. NYU, Leonard N Stern Sch Business, New York, NY 10012 USA. Garud, R, NYU, Leonard N Stern Sch Business, 7-13 Tisch Hall,40 W 4th St, New York, NY 10012 USA.: 25-48. 
Garud, Raghu, and MA Rappa. 1994. "A Socio-Cognitive Model of Technology Evolution: The Case of Cochlear Implants.” Organization Science 5 (3): 344-62.

Geels, F, and R Raven. 2006. "Non-Linearity and Expectations in Niche-Development Trajectories: Ups and Downs in Dutch Biogas Development (1973-2003).” Technol. Anal. Strateg. 18. Eindhoven Univ Technol, NL-5600 MB Eindhoven, Netherlands. Geels, F, Eindhoven Univ Technol, IPO 2-10,POB 513, NL-5600 MB Eindhoven, Netherlands. f.w.geels@tm.tue.nl: 37592.

Geels, Frank W. 2014. "Regime Resistance against Low-Carbon Transitions: Introducing Politics and Power into the Multi-Level Perspective.” Theory, Culture \& Society, 0263276414531627.

Geels, Frank W., and Johan Schot. 2007. “Comment on 'Techno Therapy or Nurtured Niches?' by Hommels et Al. [Res. Policy 36 (7) (2007)].” Research Policy 36 (7): 1100-1101. doi:10.1016/j.respol.2007.07.004.

Geva-May, Iris. 2001. "When the Motto Is 'till Death Do Us Part': The Conceptualization and the Craft of Termination in the Public Policy Cycle.” International Journal of Public Administration 24: 263-88.

Glasbergen, P. 1996. "Learning to Manage the Environment.” Democracy and the Environment: ..., 175-93.

Grabowski, Henry G, John M Vernon, and Lacy Glenn Thomas. 1978. "Estimating the Effects of Regulation on Innovation: An International Comparative Analysis of the Pharmaceutical Industry.” Journal of Law and Economics 21: 133-63.

Grin, J, and A Loeber. 2006. “Theories of Policy Learning: Agency, Structure, and Change.” In Handbook of Public Policy Analysis. London: Taylor and Francis.

Grin, J., and H. van de Graaf. 1996. “Technology Assessment as Learning.” Science, Technology \& Human Values 21 (1): 72-99. doi:10.1177/016224399602100104.

Grin, John, and Henk Van de Graaf. 1996. “Technology Assessment as Learning.” Science, Technology \& Human Values 21: 72-99.

Hall, PA. 1993. "Policy Paradigms, Social Learning, and the State: The Case of Economic Policymaking in Britain.” Comparative Politics 25 (3): 275-96.

Hommels, A, P Peters, and WE Bijker. 2007. "Techno Therapy or Nurtured Niches? Technology Studies and the Evaluation of Radical Innovations.” Research Policy.

Hoogma, R, R Kemp, J Schot, and B Truffer. 2002. Experimenting for Sustainable Transport: The Approach of Strategic Niche Management. London/New York: Spon Press.

Irwin, Alan, Henry Rothstein, Steven Yearley, and Elaine McCarthy. 1997. "Regulatory scienceTowards a Sociological Framework.” Futures 29 (1): 17-31. doi:10.1016/S0016-3287(96)000638.

Kemp, R, J Schot, and R Hoogma. 1998. "Regime Shifts to Sustainability through Processes of Niche Formation: The Approach of Strategic Niche Management.” Technology Analysis \& Strategic Management 10: 175-98. 
Kemp, René, and Serena Pontoglio. 2011. “The Innovation Effects of Environmental Policy Instruments - A Typical Case of the Blind Men and the Elephant?” Ecological Economics 72 (December): 28-36. doi:10.1016/j.ecolecon.2011.09.014.

Kemp, René, Johan Schot, and Remco Hoogma. 1998. "Regime Shifts to Sustainability through Processes of Niche Formation: The Approach of Strategic Niche Management.” Technology Analysis \& Strategic Management Strategic Management 10 (2). Routledge: 175-98. doi:10.1080/09537329808524310.

Kern, Florian. 2011. "Ideas, Institutions, and Interests: Explaining Policy Divergence in Fostering 'System Innovations’ towards Sustainability.” Environment and Planning-Part C 29: 1117.

Kok, Robert, Fabian van der Linden, Richard Smokers, and Maarten Verbeek. 2014. Evaluatie Autogerelateerde Belastingen 2008-2013 En Vooruitblik Automarktontwikkelingen Tot 2020. Policy Research Corporation \& TNO.

Lockwood, Matthew. 2015. "Creating Protective Space for Innovation in Electricity Distribution Networks in Great Britain: The Politics of Institutional Change.” Environmental Innovation and Societal Transitions, no. This issue.

Majone, G., and Aaron B. Wildavsky. 1979. "Implementation as Evolution.” In Implementation, edited by Jeffrey Pressman and Aaron B. Wildavsky. Berkeley: University of California Press.

Markard, Jochen, Marco Suter, and Karin Ingold. 2015. "Socio-Technical Transitions and Policy Change - Advocacy Coalitions in Swiss Energy Policy.” Environmental Innovation and Societal Transitions, no. This issue.

May, PJ. 1992. "Policy Learning and Failure.” Journal of Public Policy.

Mayer, M. 2006. "Listen to All the Voices: An Advocate’s Perspective on Early Access to Investigational Therapies.” Clinical Trials.

Meijer, Albert, Wouter Boon, and Ellen Moors. 2013. "Stakeholder Engagement in Pharmaceutical Regulation: Connecting Technical Expertise and Lay Knowledge in Risk Monitoring." Public Administration 91: 696-711.

Munos, Bernard. 2009. "Lessons from 60 Years of Pharmaceutical Innovation.” Nature Reviews Drug Discovery 8: 959-68.

Negro, Simona O, Floortje Alkemade, and Marko P Hekkert. 2012. "Why Does Renewable Energy Diffuse so Slowly? A Review of Innovation System Problems.” Renewable and Sustainable Energy Reviews 16: 3836-46. doi:http://dx.doi.org/10.1016/j.rser.2012.03.043.

Nill, J, and R Kemp. 2009. "Evolutionary Approaches for Sustainable Innovation Policies: From Niche to Paradigm?” Research Policy.

Porter, ME, and C Van der Linde. 1995. "Toward a New Conception of the EnvironmentCompetitiveness Relationship.” The Journal of Economic Perspectives 9 (4): 97-118.

Raven, Rob, Florian Kern, Bram Verhees, and Adrian Smith. 2015. "Niche Construction and Empowerment through Socio-Political Work. A Meta-Analysis of Six Low-Carbon Technology Cases.” Environmental Innovation and Societal Transitions, no. This issue. doi:http://dx.doi.org/10.1016/j.eist.2015.02.002. 
Raven, Rob P.J.M. 2006. “Towards Alternative Trajectories? Reconfigurations in the Dutch Electricity Regime.” Research Policy 35 (4): 581-95.

Rip, Arie. 1995. "Introduction of New Technology: Making Use of Recent Insights from Sociolcmgy and Economics of Technology.” Technology Analysis \& Strategic Management 7 (4). Routledge: 417-32. doi:10.1080/09537329508524223.

Roberts, T. G., and B.A. Chabner. 2004. "Beyond Fast Track for Drug Approvals.” New England Journal of Medicine 351: 501-5.

Rothwell, Roy. 1992. "Industrial Innovation and Government Environmental Regulation: Some Lessons from the Past.” Technovation 12: 447-58.

Sabatier, P. A. 1993. "Policy Change over a Decade or More.” In Policy Change and Learning: An Advocacy Coalition Approach (theoritical Lenses on Public Policy), edited by P. A. Sabatier and H. C. Jenkins-Smith, 13-39. Boulder: Westview Press.

Sabatier, Paul A. 1993. “Policy Change over a Decade or More.” In Policy Change and Learning: An Advocacy Coalition Approach (theoritical Lenses on Public Policy), edited by Paul A Sabatier and Hank C Jenkins-Smith, 13-39. Boulder: Westview Press.

Scannell, Jack W, Alex Blanckley, Helen Boldon, and Brian Warrington. 2012. "Diagnosing the Decline in Pharmaceutical R\&D Efficiency.” Nature Reviews Drug Discovery 11: 191-200.

Schneider, Anne L., and Helen M. Ingram. 1997. Policy Design for Democracy. Kansas: University Press of Kansas.

Schot, J., R. Hoogma, and B. Elzen. 1994. "Strategies for Shifting Technological Systems : The Case of the Automobile System.” Futures 26 (10): 1060-76.

Schot, Johan, and Frank W. Geels. 2008. "Strategic Niche Management and Sustainable Innovation Journeys: Theory, Findings, Research Agenda, and Policy.” Technology Analysis \& Strategic Management 20 (5): 537-54. doi:10.1080/09537320802292651.

Sierzchula, William, Sjoerd Bakker, Kees Maat, and Bert Van Wee. 2012a. “Technological Diversity of Emerging Eco-Innovations: A Case Study of the Automobile Industry.” Journal of Cleaner Production 37: 211-20.

_ 2012b. "The Competitive Environment of Electric Vehicles: An Analysis of Prototype and Production Models.” Environmental Innovation and Societal Transitions 2: 49-65.

2014. "The Influence of Financial Incentives and Other Socio-Economic Factors on Electric Vehicle Adoption.” Energy Policy 68: 183-94.

Smith, A, and A Stirling. 2010. "The Politics of Social-Ecological Resilience and Sustainable SocioTechnical Transitions.” Ecology and Society 15: online.

Smith, A, A Stirling, and F Berkhout. 2005. "The Governance of Sustainable Socio-Technical Transitions.” Research Policy 34. Univ Sussex, SPRU Sci \& Technol Policy Res, Freeman Ctr, Brighton BN1 9QE, E Sussex, England. Vrije Univ Amsterdam, NL-1087 HV Amsterdam, Netherlands. Smith, A, Univ Sussex, SPRU Sci \& Technol Policy Res, Freeman Ctr, Brighton BN1 9QE, E Sussex, England. : 1491-1510. 
Smith, Adrian, and Rob Raven. 2012. "What Is Protective Space? Reconsidering Niches in Transitions to Sustainability.” Research Policy 41 (6). Elsevier B.V.: 1025-36.

doi:10.1016/j.respol.2011.12.012.

Stewart, Luke A. 2010. The Impact of Regulation on Innovation in the United States: A Cross-Industry Literature Review. Washington.

Trip, J. J., J. Lima, and S. Bakker. 2012. Electric Mobility Policies in the North Sea Region Countries. Report for E-Mobility NSR. Delft.

Ulmanen, JH, GPJ Verbong, and RPJM Raven. 2009. "Biofuel Developments in Sweden and the Netherlands: Protection and Socio-Technical Change in a Long-Term Perspective.” Renewable and Sustainable ... 13 (6-7): 1406-17.

Ven, AH Van de, DE Polley, R Garud, and S Venkataraman. 1999. “The Innovation Journey.”

Voß, Jan-Peter, Adrian Smith, and John Grin. 2009. "Designing Long-Term Policy: Rethinking Transition Management.” Policy Sciences 42 (4): 275-302. doi:10.1007/s11077-009-9103-5.

Wells, P, and P Nieuwenhuis. 2012. "Transition Failure: Understanding Continuity in the Automotive Industry.” Technological Forecasting and Social Change 79: 1681-92.

Wesseling, J H, J C M Farla, D Sperling, and M P Hekkert. 2014. “Car Manufacturers’ Changing Political Strategies on the ZEV Mandate.” Transportation Research Part D: Transport and Environment, available online.

Wieczorek, Anna W, M Hekkert, and R E H M Smits. 2009. Contemporary Innovation Policy and Instruments: Challenges and Implications. ISU Working Paper Series. Utrecht University.

Wiener, Jonathan B. 2004. "The Regulation of Technology, and the Technology of Regulation.” Technology in Society 26: 483-500. 